\title{
Study on land use change in Ge Yu city Nature Reserve
}

Lingjun Meng ${ }^{1,2}$, Fang Liu ${ }^{3}$, Zhongke Feng ${ }^{1,3 *}$ and Jinying Gu ${ }^{3}$

1. College of Geographical Science, Harbin Normal University, Harbin 150025, China.

2. School of Continuing Education, Heilongjiang University, Harbin 150080, China.

\section{Beijing Forestry University, Beijing Municipal Key Laboratory of Precision Forestry, Beijing 100083, China.}

\section{* Corresponding author:Zhongke Feng Email: fengzhongke@126.com}

Key words: Land use; GIS; Nature reserve; Change analysis

Abstract: The establishment of nature reserves is one of important ways and measures to protect biodiversity, which plays an important role in maintaining balance of regional ecology, and promoting scientific research. To analysis the using and covering of land in the studied area and the variety of landscape pattern, this paper selected two issue of Landsat TM image data, which is based on GeYu city as the study area in 2009 and 2013. Combined with RS and GIS technology, which is showed that the trend of increase in cultivated land, construction land and transportation land area; Garden land, forest land, grassland and other land area is declining, and basic of water remains unchanged.

\section{Introduction}

The variety of useing and covering in Land (LUCC) refers to the complexible changes, which is caused by the interaction between the earth's environment and human activity in different time spatial scales ${ }^{[1-2]}$. To explore the land changes of useing and covering, and then analysis the comprehensive influence of LUCC for the problems of regional ecological environment, pattern of ecological system and biological diversity. Improving the problem of irrational use of land from a certain extent, to relieve the contradiction between people and land, and to realize the rational use of land resources.

The nature reserve of Ge Yu city is Langfang city county area, which has the forest ecosystem of shelter forest system as the key protection object, acting as the natural barrier, playing the important functions such as conserving soil and water, regulating climate and maintaining species diversity. However, in recent years, because of the increase and intension of population, the speed of urban construction and development, the activities of human beings and the degree of disturbance are increasing. The structure of land use types in reserve and landscape pattern have taken place in the varying degree change and degradation. Given the importance of the Ge Yu city nature reserve, we analyze the varieties of land used. And landscape features of the reserve are provided comprehensively. Accurate information and scientific basis of protection are provided by reserving resources, development and utilization, and sustainable development in the future.

\section{Research methods}

\section{General situation of the study area}

$\mathrm{Ge} \mathrm{Yu}$ city nature reserve is located in Langfang City, which is the territory of east Ge Yu Cheng $\left(116^{\circ} 47 \mathrm{E} \sim 116^{\circ} 53^{\prime} \mathrm{E}, 39^{\circ} 13^{\prime} \mathrm{N} \sim 39^{\circ} 18^{\prime} \mathrm{N}\right)$. The area is located in the depression of the Bohai sea, due to the various impact of the Yong Ding river fillers accumulate the form of mainland sink phenomenon, but sediment is thick, the range is from 1000 meters to 3000 meters. Average annual temperature is 11.4 degrees Celsius, annual average rainfall is $546.5 \mathrm{~mm}$, frost-free period lasts 181 
days.

\section{Data source and data processing}

This paper selects two issue of remote sensing images in 2009 and 2013, and Ge Yu city (county) nature reserve development and construction planning, protection area comprehensive inspection report and other text data as well as the nature reserve 1:10 000 topographic map and functional partition vector diagram etc.

By the means of geometric correction, registration, cutting and using object-oriented method to interpret the two issue of remote sensing image. At the same time, according to the industry standard of environmental protection (HJ/T192-20), the land types are divided into cultivated land, garden land, forest land, water area, grass land, construction land, transportation land and other land. To consolidate the results of classification processing, and finally formed classification diagram of the study area land use.

\section{Calculation of the land use/cover change index}

The analysis of the process and trend of using change land can be quantitatively characterized by various index models ${ }^{[3]}$. This paper selects the change extent of land use, the speed of land use change, the transfer matrix of land use change and land use change degree of 4 kinds of change index to study the land use status of the study area, the mathematical expression of the index is as follows:

(1) the extent of land use change can reflect the number and structure of land use change ${ }^{[4]}$, the calculation formula is:

$$
\Delta U=\left(U_{b}-U_{a}\right)
$$

In the formula: $\Delta U$ is the total change range of the land tape during the study period, $U_{a} 、 U_{b}$ are the numbers of land tapes area at the beginning and the end of the study, $T$ is the fixed number of year of the study period.

(2) Land use change speed. The formula ${ }^{[5]}$ is as follow:

$$
\mathrm{K}=\frac{\left(U_{b}-U_{a}\right)}{U_{a}} \times \frac{1}{\mathrm{~T}} \times 100 \%
$$

In the formula: $\mathrm{K}$ is dynamic degree of land use types in a certain period of time; $\mathrm{U}_{\mathrm{a}}$ is the area of some land type in the initial stage of the study ; $\mathrm{U}_{\mathrm{b}}$ is the area of some land type at the end of the study; $\mathrm{T}$ refers to study time limit, When the time scale of $\mathrm{T}$ represent years , the $\mathrm{K}$ value is the average annual change rate of the land use types in this area.

Comprehensive land use dynamic change speed can reflect a certain research area within a certain period of time the speed of the overall changes in land type ${ }^{[6]}$, the computation formula is as follows:

$$
\mathrm{LC}=\left[\frac{\sum_{i=1}^{\mathrm{n}} \Delta L U_{i-j}}{2 \sum_{i=1}^{n} L U_{i}}\right] \times \frac{1}{T} \times 100 \%
$$

In the formula: LC refers to the comprehensive dynamic degree of land use in a region of the study area within the scope of study time; $L U_{i}$ refers to the area of the class $i$ land at the beginning of the study of land use types; $\Delta L U_{i-j}$ refers to area absolute value which is translated from class $\mathrm{i}$ 
during the study period; $T$ refers to the study time limit, When the time scale of $\mathrm{T}$ represent years , LC refers to the comprehensive land use dynamic change rate in a certain period of time of a region of the study area.

(3) The transfer matrix of and use change.Generally indicated by the change rate $\mathrm{K}$, where the various land use types of $K+1$ period relative to the change degree in $K$ period $^{[7]}$ :

$$
\begin{gathered}
A_{i j}=\left[\begin{array}{c}
A_{11} A_{12} \cdots A_{1 n} \\
A_{21} A_{22} \cdots A_{2 n} \\
A_{n 1} A_{n 2} \cdots A_{n n}
\end{array}\right] \\
\mathbf{N}=\left\{\sum_{j=1}^{n} A_{i j}-\sum_{i=1}^{n} A_{i j}\right\} \times 100 / \sum_{j=1}^{n} A_{i j}
\end{gathered}
$$

In the formula: A refers to the area ; $\mathrm{n}$ refers to land landscape and land use type; i refers to the area of land at the beginning of the study, $\mathrm{j}$ refers to the area of land at the end of the study.

(4) The change index of land use degree can not only highlight a specific attribute of the land resources itself, but also can reflect the social attributes of the interaction between all kinds of natural factors such as human factors and natural factors. The model ${ }^{[8-9]}$ is:

$$
L=100 \times \sum_{i=1}^{n} A_{i} \times C_{i}
$$

In the formula: $\mathrm{L}$ refers to the comprehensive index of land use degree; $\mathrm{A}_{\mathrm{i}}$ refers to the level $\mathrm{i}$ classification index of land use degree; $C_{i}$ refers to the level i classification area ratio of land use degree; $\mathrm{n}$ refers to the classification number of land use degree.

\section{Results and analysis of land use/cover change}

Interpretation is obtained from the classification figure of Ge Yu city nature reserve land in 2009 and 2013, based on the above index formula of model, used the statistical analysis function of software ArcGIS10.1, which is combined with Excel software and eventually get the quantitative value of each index, the results is showed in table 1 and table 2.

Table 1 The extent of GeYu city nature reserves land use change from 2009 to2013

\begin{tabular}{llcc}
\hline Land use type & Area of 2009(m2) & Area of 2013(m2) & $\begin{array}{c}\text { Total variation range } \\
\text { of 2009-2013 }\end{array}$ \\
& & & $(\mathrm{m} 2)$ \\
\hline Cultivated land & 23700964.93 & 24699668.96 & 998704.03 \\
Garden land & 10657728.27 & 10384967.80 & -272760.47 \\
Forest land & 10281007.35 & 8469896.35 & -1811111 \\
Grass land & 424281.48 & 3774773.05 & -46808.43 \\
Waters & 1106326.18 & 1105838.79 & -487.39 \\
Transportation land & 415603.54 & 966942.99 & 551339.45 \\
Construction land & 6305616.79 & 6956077.81 & 650461.02 \\
Other land & 487139.06 & 417801.85 & -69337.21 \\
\hline
\end{tabular}


Table 2 GeYu city kind of single land use dynamic degree around the nature reserve from 2009 to 2013

\begin{tabular}{lccc}
\hline \multicolumn{1}{c}{ Land use type } & Area of $2009\left(\mathrm{~m}^{2}\right)$ & Area of $2013\left(\mathrm{~m}^{2}\right)$ & $\begin{array}{c}2009-2013 \\
\text { single land use } \\
\text { dynamics }(\%)\end{array}$ \\
\hline Cultivated land & 23700964.93 & 24699668.96 & 1.05 \\
Garden land & 10657728.27 & 10384967.80 & -0.64 \\
Forest land & 10281007.35 & 8469896.35 & -4.40 \\
Grass land & 424281.48 & 377473.05 & -2.76 \\
Waters & 1106326.18 & 1105838.79 & -0.01 \\
Transportation land & 415603.54 & 966942.99 & 33.16 \\
Construction land & 6305616.79 & 6956077.81 & 2.58 \\
Other land & 487139.06 & 417801.85 & -3.56 \\
\hline
\end{tabular}

Known from the analysis of table 1 and table 2, from 2009 to 2013, during the research of the reserve land use quantity and structure have taken place a certain range of changes, and its change range in the order: forest land >cultivated land>construction land >transportation land $>$ other land $>$ garden land $>$ grass land $>$ waters. The speed of dynamic change of various land use type also have greatly different, speed of change in the order:transportation land $>$ forest land $>$ grass land $>$ construction land $>$ cultivated land $>$ garden land $>$ other land $>$ waters, which transportation land use change significantly, the growth rate is $33.16 \%$.

Table 3 GeYu city nature reserve from 2009 to 2013, the transfer matrix of land use change (\%)

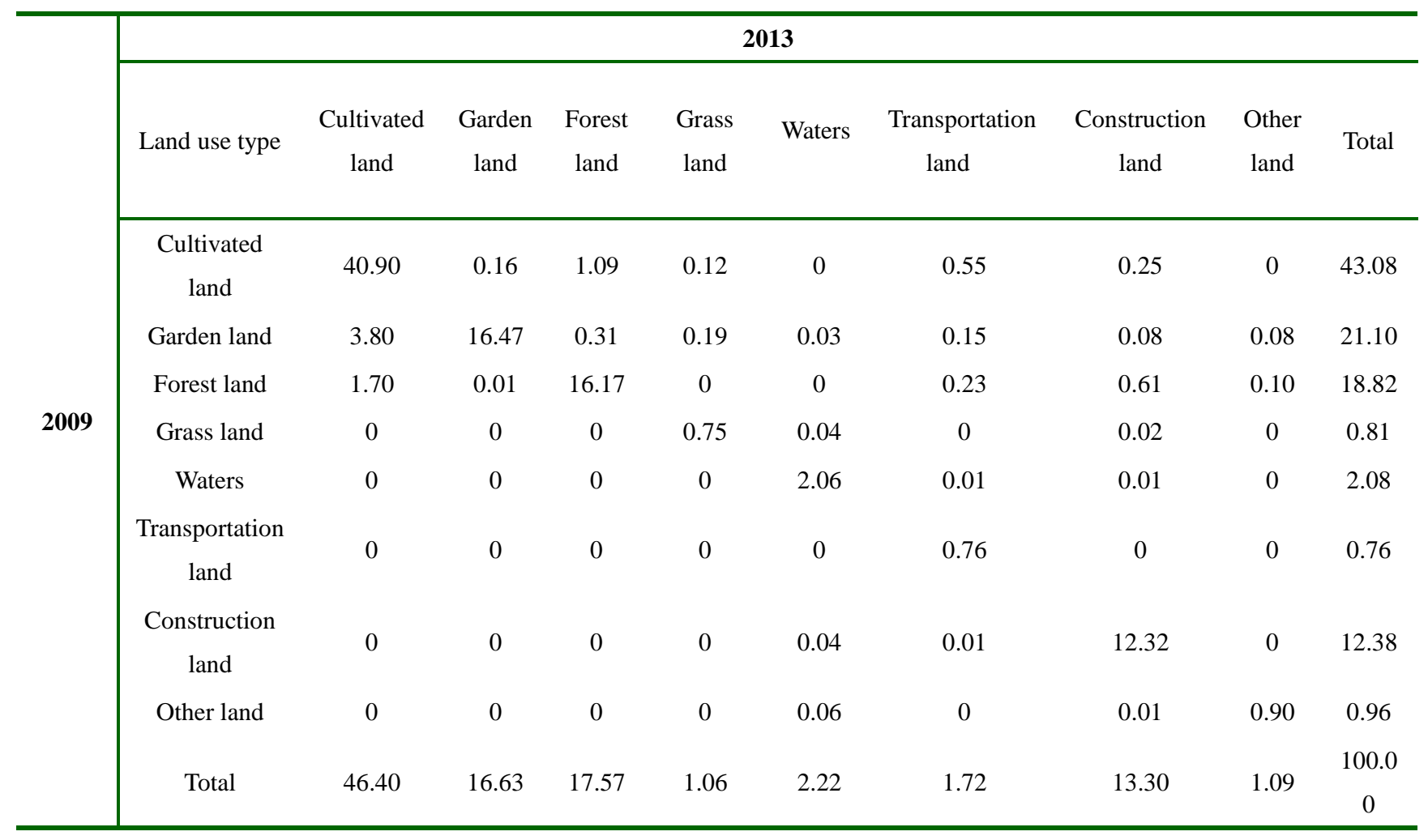


Note a: " 0 " represents no change in area between land types on the time span

Using the formula 3, combining the land use types of Ge Yu city nature reserve in 2009 and 2013 , the integrated dynamic of land use in study area is calculated value of $1.21 \%$, the average annual rate of change of land use is low,which means the conversion speed of land use types in Ge Yu city nature reserve is not fast.

Table 4,2009-2013, comprehensive index of land use degree

\begin{tabular}{cccc}
\hline Year & Comprehensive index & Change quantity & Change rate \\
\hline 2009 & 288.64 & & \\
2013 & 294.63 & 5.99 & 0.02 \\
\hline
\end{tabular}

According to table 3 and table 4 from 2009 to 2013, land use types of reserves between the cultivated land, garden land and forest land had a close transforming relationship, and followed by the cultivated land transformed into construction land and transportation land; Construction land mainly transformed from forest land, waters, grassland and other land; The grass transformed into waters; Forest land and cultivated land transformed into grassland; The results highlight such changes of the reserves took place in the trend of deviating between the patterns of the ecological system and reserve sustainable development,which were mainly related to the natural conditions,local economic development and urban construction.

\section{Conclusion}

According to the spatial and temporal variation analysis of land use types, land use types in the study area are mainly cultivated land, garden land and forest land.Three the land coverage area account for more than $80 \%$ of the total area from 2009 to 2013, other individual land types on the changes are obvious, but due to the coverage area is lesser, the influence degree is weak for the whole study area.

Comprehensive analysis shows that with the increase of population and the improvement of urban construction, the demand of land use of urban construction, industrial and mining industry, transportation and others is gradually increasing at the expense of occupying cultivated land and forest land of reserves, which makes the area of forest land and garden land falling, lead to ecological landscape types of reserve tend to be simple, ecological pattern has a slow change;Since the landscape types functioning natural ecological environment are mainly cultivated land, garden land, forest land and waters, the natural resources for maintain biodiversity of the whole area are damaged with the falling of ecosystem structure stability.

\section{Acknowledgements}

This research has been finished by the Geographical Science of Normal University, Continuing Education, of Heilongjiang University, and Beijing Municipal Key Laboratory of Precision Forestry in Beijing Forestry University.Thanks to my tutor professor Zhongke Feng for his guidance and correction to this article. And also grateful to classmates for field investigation together.

\section{References}

[1] Zhang Y., Liu Y.F., Ding Q., 1996-2006 Analysis on Land Utilization/Cover in Wuhan City[J]. Ecology and

Environmental Science, 2010, 19(11):2534-2539. in Chinese 
[2] Jiang, P.H., Zhao ,R.F., and Zhao, H.L., Land Utilization of the Area of the middle of Heihe River since

1975/LandCover Change and Spatial-temporal Evolution[J]. Journal of Ecology and Environment, 2012,

28(5):473-479. in Chinese

[3] He ,B.H., X.X., Gu ,S.X., Analysis on Tongnan County Land Utilization Landscape character[J]. Studies on

the Soil Erosion, 2006, 12(5):130-133. in Chinese

[4] Cai, Y.L., Study on Land Use/Cover Change-Finding New Way of Research[J]. Geographic Research 2001,

(6):645-652. in Chinese

[5] Sun, Y., Liu, Z.Q., and Wang, Q.B., Analysis on Land Utilization Spatial Expansion and Driving Force[J].

Resources Science. 2011(11):2022-2029. in Chinese

[6] Gao, Y., S, F.Z., and Sun, X.Y,.Analysis on Land Utilization Coastal Zone of Guangdong Province and DrivingForce[J]. Acta Oceanologica Sinica(Chinese Version). 2011(4):95-103. in Chinese

[7] Liu, H.Y., Wet Landscap Change and Environmental Effect[M]. Beijing:Science Press, 2005:115-116. in Chinese

[8] Li, J., He, Z.W., and Xu, H.X.,Dynamic Change Studies on Land Utilization before and after the earthquake inDujiangyan City [J]. Journal of Sichuan Normal University(Natural Sciences). 2012(3):412-417. in Chinese

[9] Su, R.H., Land Utilization of Henan Province/Studies on Land Cover Change and Driving factor [D]. Heibei

Normal University,2008. in Chinese

[10] Wang, J., Xiong, N.N., and Dong, B., Change Analysis on Land Utilization Landscape Pattern acording RS in 20years [J]. Journal of Northeast Forestry University.2008(S1):83-88. in Chinese

[11] Gao, Y.,Su, F.Z., and Sun, X.Y.,Studies on Land Utilization of Costal Area of Guangdong Province and Drivingforce[J]. Acta Oceanologica Sinica 2011(4):95-103. in Chinese 